\title{
The Economics of Rural Electrification Projects: Theory and Case Study of Pakistan
}

\author{
MARK W. GELLERSON*
}

Developing countries will invest significant resources in rural electrification projects in the $1980 \mathrm{~s}$. Up to now, there has been little discussion in the economics literature concerning the appropriate method of evaluating such projects. This paper outlines such a methodology and, then, it is applied in a case-study of a proposed rural electrification project in Pakistan. Finally, important areas for future research are identified.

\section{INTRODUCTION}

Electricity consumption in developing countries is projected to grow at an average annual rate of 8.5 percent during the $1980 \mathrm{~s}$. The investment necessary to meet such increased consumption will be approximately US $\$ 414$ billion (in constant 1980 \$) [4], ${ }^{1}$ and a significant fraction of this investment will be utilized in rural electrification projects. Since a large amount of economic resources will be committed to such projects, it is important that an appropriate methodology for evaluating these projects be available. As yet, however, little discussion has occurred within the economics literature concerning how such projects should be evaluated. One approach is described in Section II of this paper. Then, in Section III, this methodology is applied in a case study of a proposed rural electrification project in Pakistan. Finally, results of the case study are summarized in Section IV wherein important areas for future research have also been identified.

\section{EVALUATING RURAL ELECTRIFICATION PROJECTS}

The purpose of evaluating a rural electrification project is to determine whether the project represents an efficient use of a country's resources. The basic approach used is first to estimate a benefit-cost ratio, or economic internal rate of return, for the project and then to supplement this calculation with a consideration

* The author is Assistant Professor of Economics in the Southern Illinois University, Carbondale, Illinois (U.S.A.).

${ }^{1} \mathrm{~A}$ general discussion of the process of rural electrification in developing countries is found in Anderson and Turvey [1] . 
of some of the non-quantifiable benefits associated with the project. As with many types of projects, the most difficult part of the evaluation procedure is the estimation of benefits. The estimation of project costs is more straightforward, although it may be necessary to use extensive shadow pricing. In this section, the nature of economic benefits resulting from rural electrification is described and then an approach for estimating these benefits is outlined. Finally, the procedure used to estimate the economic costs of rural electrification is explained.

\section{Benefits}

A variety of economic benefits may result from bringing electricity to nonelectrified areas. The principal benefits which can be treated in an economic analysis take the form of (i) cost savings, resulting from the substitution of electricity for more costly sources of energy, and (ii) increased economic activity generated by the new opportunities which exist, both for households and commercial establishments, after electrification. Other benefits such as improved health-care and educational opportunities, and increased security at night may result. However, it is difficult to quantify such benefits and they are typically treated only in a qualitative fashion.

Benefit Estimation. Assuming that consumers are rational decision makers, electricity must provide benefits to them worth at least as much as they pay for electricity. Thus estimates of tariff revenues in the electrification areas provide a minimum estimate of direct benefits resulting from electrification. However, consumers may actually be willing to pay more than is indicated by tariff revenues, i.e. there may be positive consumer surplus. $^{2}$ This will be the case if consumers were formerly paying more for some alternative source of energy than they will pay with electricity. Such surplus benefits would be equivalent to the area $\mathrm{ABCD}$ in Figure 1, where $P_{s}$ and $P_{e}$ equal the per unit financial costs of energy supplied from the substitute energy source and electricity respectively, and $Q_{s}$ and $Q_{e}$ equal the quantities of energy consumed prior to and after electrification respectively. In this case, surplus benefits can be estimated as:

$$
Q_{s}\left(P_{s}-P_{e}\right)+1 / 2\left(Q_{e}-Q_{s}\right)\left(P_{s}-P_{e}\right) .
$$

${ }^{2}$ This consumer surplus results because of cost savings realized by electricity consumers. A practical method of estimating cost savings, and hence surplus benefits, is the following:

(1) Assume an average level of annual energy consumption per consumer.

(2) Determine the annual cost to the consumer of this energy if it comes from: (a) some alternative source, e.g. kerosene for lighting or diesel motors for motive power, or (b) from electricity. For any particular energy source, this annual cost equals the cost of the energy itself

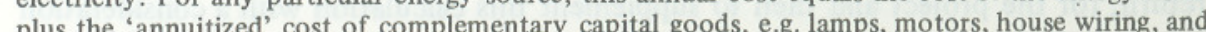
plus the 'annuitized' cost of complementary capital goods, e.g. lamps, motors, house wiring, and so on.

(3) If (2a) is greater than (2b), then the difference is the cost savings (or surplus benefit) to a particular type of consumer resulting from electrification. This estimate of cost savings can then be multiplied by the number of consumers of the given type in order to estimate total surplus benefits for that type of consumers during a given time period.

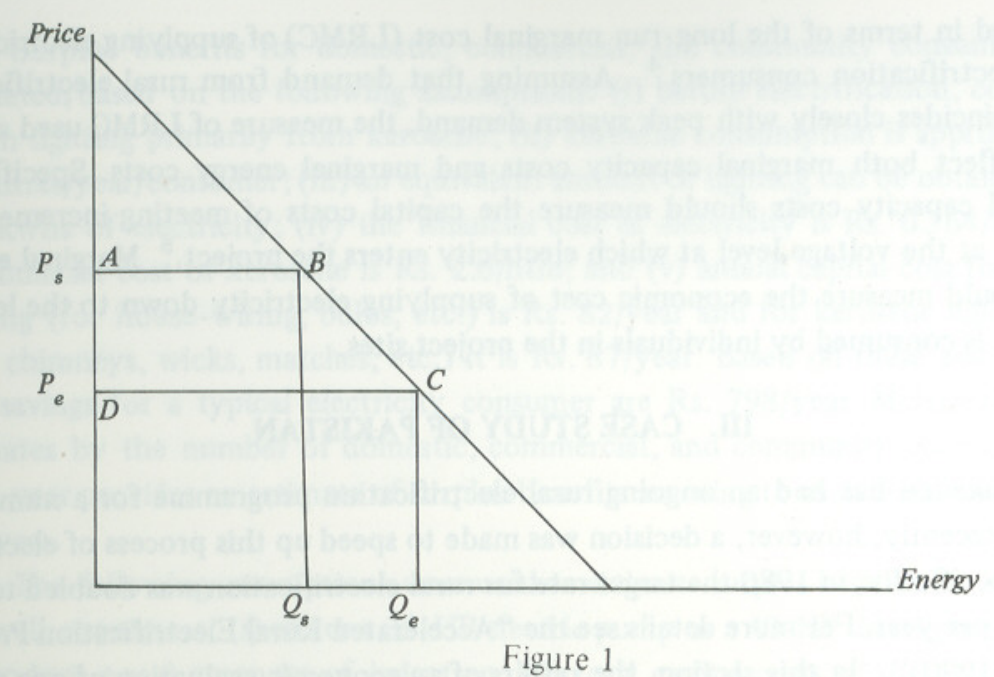

Benifits to Consumers for Rural Electrification

In order to use the method of estimating benefits described above, it is necessary to develop accurate load forecasts (and hence estimates of tariff revenues). Load forecasts can be made on the basis of (i) previous experiences with rural electrification in similar regions in the same (or another) country, or (ii) surveys of potential consumers to determine both what they are currently paying for alternative energy sources and their willingness to pay for electricity at the proposed tariff levels. Using either approach, one should determine a basis for estimating average levels of consumption per consumer, the rate at which this consumption increases, and the rate at which the number of consumers increases.

\section{Costs and their Estimation}

The costs of a rural electrification project can be divided into investment and operating costs. Investment costs include the costs of constructing the project itself, i.e. the costs of purchasing and installing $11-\mathrm{KV}$ and $.4-\mathrm{KV}$ lines, transformers, service connections, and so on, plus overhead costs and house-wiring costs. These costs should be measured in constant prices (using the most recent prices available) and should be net of any duties or taxes. ${ }^{3}$ Depending on local market conditions, it may be appropriate to use shadow prices for labour costs and foreign exchange costs.

Operating costs consist primarily of energy costs plus maintenance costs. Energy costs will account for a relatively large fraction of total project costs over the project's lifetime; and, therefore, it is especially important that these costs be

${ }^{3}$ Duties or taxes are not included since they reflect transfers of resources rather than the actual consumption of resources. 
measured in terms of the long-run marginal cost (LRMC) of supplying electricity to rural electrification consumers. ${ }^{4}$ Assuming that demand from rural electrification areas coincides closely with peak system demand, the measure of LRMC used should then reflect both marginal capacity costs and marginal energy costs. Specifically, marginal capacity costs should measure the capital costs of meeting increments in demand at the voltage level at which electricity enters the project. ${ }^{5}$ Marginal energy cost should measure the economic cost of supplying electricity down to the level at which it is consumed by individuals in the project sites.

\section{CASE STUDY OF PAKISTAN}

Pakistan has had an ongoing rural electrification programme for a number of years. Recently, however, a decision was made to speed up this process of electrification. Specifically, in 1980 the target rate for rural electrification was doubled to 2000 villages per year. For more details see the "Accelerated Rural Electrification Program (1981-1990)"'. In this section, the results of an economic evaluation of one part of this accelerated rural electrification programme will be described. ${ }^{6}$ Separate analyses were done for each of the provincial electrification schemes since there are significant variations in both average benefits and average costs for typical schemes in different provinces.

Different types of consumers will gain different amounts of benefits from electrification. Specifically, domestic, commercial, community, small industry, and tubewell consumers are apt to be the principal beneficiaries since all will realize cost savings as a result of electrification. Such cost savings mean that consumer surplus benefits accrue to these consumers. Specific details concerning the estimation of surplus benefits for various types of consumers are provided below.

4The theoretical basis for marginal cost pricing is developed in Williamson [7] and Steiner 6]. For a more practical discussion of how to apply the tenets of marginal cost pricing in actual tariff studies, see Munasinghe [2].

In general, marginal generation capacity cost equals the per $\mathrm{kW}$ 'annuitized' cost for the enerating unit used to meet marginal increments in peak demand. Marginal transmission or distribution capacity cost equals the average incremental cost (AIC) of transmission or distribution. For example, AIC for transmission equals

$$
\sum_{t=1}^{N} \frac{C_{t} /(1+r)^{t}}{d_{t /(1+r)^{t}}}
$$

Where $C_{t}=$ the cost of transmission capacity investment in year $t, d=$ the increment in maximum demand at the transmission voltage level in year $t$, and $r=$ the discount rate. For more details, see Munasinghe [2].

${ }^{6}$ Seven hundred additional villages are scheduled to be electrified in $1982-83$ as a result of foreign assistance. These villages are within 1.5 miles of the existing 11-KV lines in the Punjab, Sind, and the N.-W.F.P. (North-West Frontier Province), and within 6 miles in Baluchistan. Sind, and these villages have populations of at least 1000 in the Punjab and Sind and of at least addition, these villages have populations of at least 1000 in the Punjab and Sind, and of at least
300 in the N.-W.F.P. and Baluchistan.
Surplus benefits for domestic, commercial, and community consumers were estimated, based on the following assumptions: (i) before electrification, consumer obtain lighting primarily from kerosene; (ii) kerosene consumption is approximately 360 litres/year/consumer; (iii) an equivalent amount of lighting can be obtained from $259 \mathrm{kWhs}$ of electricity; (iv) the financial cost of electricity is Rs. $0.364 / \mathrm{kWh}$ and the financial cost of kerosene is Rs. 2.6/litre; and (v) annual capital cost for electric lighting (for house-wiring, bulbs, etc.) is Rs. 82/year and for kerosene lighting (for glass chimneys, wicks, matches, etc.) it is Rs. $87 /$ year. Based on these assumptions, cost savings for a typical electricity consumer are Rs. 798/year. Multiplying these estimates by the number of domestic, commercial, and community consumers in given year provides an estimate of surplus benefits accruing to such consumers during that year.

The following assumptions were used to estimate surplus benefits for irrigation tubewell consumers: (i) either a 35-HP electric pump or a 40-HP diesel pump is used to produce equal amounts of irrigation; (ii) total capital costs of such electric and diesel pumps are Rs. 14,500 and Rs. 45,000 respectively, while annual maintenance costs are Rs. 6,700 and Rs. 9,000 respectively; (iii) annual energy consumption is 960 gallons of diesel fuel and 82 gallons of Mobil oil for the diesel and 17,500 kWh for the electric pump; and (iv) the cost of electricity is Rs. 0.365 in the Punjab and Sind and Rs. 0.281 in the N.-W.F.P. and Baluchistan while the costs of diesel fue and Mobil oil are Rs. 13.68/gallon and Rs. 14/gallon respectively. Cost savings fo the typical tubewell consumer are estimated to be Rs. 15,236/year in the Punjab and Sind but Rs. 16,706/year in the N.-W.F.P. and Baluchistan.

Finally, surplus benefits for small industrial consumers such as flour mills or sawmills were estimated using the following assumptions: (i) either a 25-HP diese motor or a 15-HP electric motor is used, the capital cost of the former being Rs. 25,300 and of the latter Rs. 18,400; (ii) energy consumption is 1,170 gallons of diesel fuel and 99 gallons of Mobil oil for the diesel motor and 17,000 kWhs for the electric motor; (iii) annual maintenance costs are Rs. 8500 for the diesel motor and Rs. 5,900 for the electric motor; and (iv) the costs of diesel fuel and Mobil oil are a described above and the cost of electricity is Rs. $0.62 / \mathrm{kWh}$. Cost savings are estimated to be Rs. 10,312/year for a typical small industrial consumer.

Following this approach, surplus benefits were estimated for the entire project and separately for each provincial electrification scheme the 25 -year project lifetime. These benefits are greatest in the Punjab and smallest in Baluchistan; and total surplus benefits for the entire project increase from Rs. 79,202,000 in the second project-year to Rs. $600,576,000$ in the twenty-fifth project year.

Following the logic described in Section II, the direct benefits of rural electrification in each province in Pakistan for a given year equal the tariff revenues generated in that year. Again, these benefits are greatest in the Punjab and smallest in Baluchistan; and total direct benefits increase from Rs. $39,085,000$ in the second 
project-year to Rs. $320,698,000$ in the twenty-fifth project-year. Thus surplus economic benefits account for about two-thirds of the measured economic benefits resulting from the proposed rural electrification project in Pakistan.

As discussed in Section II, project costs consist of investment costs and operating costs. Estimates of investment costs were constructed by using the project bill of materials and estimates of unit costs net of any duties or taxes. Operating costs equal maintenance costs plus energy costs. Maintenance costs were assumed to equal two percent of cumulative investment costs. Energy costs equal the per $\mathrm{kWh}$ long-run marginal cost of supplying energy to consumers in the electrification areas times the load forecast in these areas. ${ }^{7}$ Long-run marginal cost per $\mathrm{kWh}$ supplied is estimated to be Rs. 1.1 per $\mathrm{kWh}$, which is significantly higher than WAPDA's bulk supply tariff of Rs. 0.37 per kWh. ${ }^{8}$

Project costs are highest in the Punjab and lowest in Baluchistan. During the first two project-years, investment costs account for about 80 percent of total project cost in those years. However, by the twenty-fifth project-year operating costs make up about 94 percent of total project costs in that year. Overall, operating costs are much more important than investment costs. Since operating costs consist primarily of energy costs, the results of the cost analysis indicate that the assumed value of the long-run marginal cost of supplying electricity is a critical determinant of project costs.

The estimates of economic benefits and costs have been used to calculate the economic internal rates of return (EIRR) for the electrification schemes in each province in Pakistan, and these are summarized in Table 1.

The EIRRs calculated for the electrification schemes in the Punjab and Sind indicate that there is a reasonably strong economic justification for rural electrification in these provinces. The justification is considerably weaker in the N.-W.F.P. and Baluchistan. There are, of course, a variety of potential benefits from rural electrification to measure which no attempt has been made in this paper. In addition, no explicit attempt has been made to consider the distributional implications of this project. Specifically, it was assumed that the marginal utility of income was the same for all consumers and that benefits accruing to different consumers were weighted equally by society. It is interesting to note, however, that the provinces for which the economic-efficiency justification of the project is weakest, the N.-W.F.P.

${ }^{7}$ The long-run marginal cost of supplying electricity within the WAPDA system has been estimated in Munasinghe and Gellerson [3]. This estimate utilizes shadow prices for unskilled labour, foreign exchange, and fuels burned in marginal generating units. Results from this study have been updated for use in analyzing this project. Specifically, allowances have been made for (a) increases in the opportunity cost of gas used in peaking plants, and (b) reductions in losses within the WAPDA (Water and Power Development Authority) system.

${ }^{8}$ The estimated long-run marginal cost of Rs. $1.1 / \mathrm{kWh}$ consists of a capacity cost of Rs. $0.06 / \mathrm{kWh}$ and an energy cost of Rs. $0.50 / \mathrm{kWh}$. The capacity charge reflects the cost of capacity down to the voltage level $(11-\mathrm{KV})$ at which electiricty enters the project, while the cost to supply energy down to the voltage level at which it is consumed. and Baluchistan, are those in which consumers are most likely to be poor. Thus if distributional consequences of the project were considered, the overall justification of the electrification schemes in the N.-W.F.P. and Baluchistan would probably be strengthened relative to those in the Punjab and Sind. ${ }^{9}$ This is because electrification in the former provinces would generate employment opportunities and ensure the availability of an important consumption good at a lower price to individuals who are among the poorest in Pakistan.

Table 1

Results of Economic Analysis

EIRR*

(\%)

1. Base Case

Punjab

Sind

N.-W.F.P.

4.2

Baluchistan

2.2

Pakistan: Total

2. Sensitivity Analysis 1

(slower growth of saturation rate)

3. Sensitivity Analysis 2

$10 \%$ increase in investment cost

$20 \%$ increase in investment cost

${ }^{*}$ Economic internal rate of return.

Insight into the factors which affect the economic return on an investment in rural electrification can be gained by considering the relevant economic characteristics of "typical" villages in the four provinces. There are significant differences in these characteristics which, in turn, lead to large variations in both the economic benefits and costs resulting from electrification. Some of the differences in economic characteristics are summarized in Table 2 . On the cost side, the most important economic characteristic appears to be the length of the 11-KV lines needed to reach the village. This length is shortest in the Punjab, which has the highest EIRR and longest in Baluchistan, which has the lowest EIRR. On the benefit side, the most

${ }^{9}$ This might be done by applying the methodology developed by Squire and Van der Tak [5]. However, the problem is to develop an appropriate set of social prices. 
important economic characteristics relate to the population of the village and, hence, to the various types of consumers who can be expected to connect once electricity is supplied. A typical village in the Punjab is larger than that in any other province and as a result can be expected to have more consumers of various types.

Table 2

Characteristics of Typical Villages in the Four Provinces

\begin{tabular}{|c|c|c|c|c|}
\hline Characteristics & Punjab & Sind & N.-W.F.P. & Baluchistan \\
\hline Average Population & 3,665 & 3,328 & 2,756 & 1,805 \\
\hline $\begin{array}{l}\text { Average Length of } \\
11 \mathrm{KV} \text { lines (miles) }\end{array}$ & 1.23 & 1.46 & 1.46 & 2.56 \\
\hline Average Number of & & & & \\
\hline $\begin{array}{l}\text { Domestic Consumers }{ }^{1} \\
\text { Average Number of }\end{array}$ & 76 & 60 & 50 & 29 \\
\hline Community Consumers ${ }^{2}$ & $3^{2} 26$ & 24 & 20 & 13 \\
\hline $\begin{array}{l}\text { Average Number of } \\
\text { Commercial Consumers } 1\end{array}$ & 2.2 & 1.9 & 1.6 & 1.3 \\
\hline $\begin{array}{l}\text { Average Number of Small } \\
\text { Industrial Consumers }{ }^{2}\end{array}$ & 2.4 & 2.2 & 1.8 & 1.3 \\
\hline $\begin{array}{l}\text { Average Number of } \\
\text { Irrigation Tubewell }\end{array}$ & & & & \\
\hline Consumers $^{3}$ & 2.6 & 2.1 & 1.7 & 1.5 \\
\hline EIRR & 14.8 & 9.0 & 4.2 & 2.2 \\
\hline
\end{tabular}

Source: WAPDA Project Paper.

1 Assumes a saturation rate of $15 \%$ of potential consumers in the first year. Assum rate of $100 \%$ of potential consumers in the first year.

3 Assumes a saturation rate of $50 \%$ of potential consumers in the first year.

The information summarized in Table 2 may be of use in the future when additional villages are selected for electrification. For example, if a minimum EIRR of 9-10 percent is needed for a village to be selected, then villages which have the same or "better" economic characteristics as those found in the "typical" village in Sind should be chosen (since the EIRR for such a village is roughly 9 percent).

Overall, the results of this economic analysis provide one type of information which is useful to those involved in formulating regional, national, and international development policies for Pakistan. Clearly, however, such policies cannot (or should not) be based solely on estimated economic internal rates of return. This is because all potential projects will result in various social or economic benefits not reflected in
rates of return. For example, funding of electrification projects in Baluchistan may serve as a catalyst for additional electrification projects (or other projects) in that province funded by external donors; or electrification may result in additional SCARP projects in the Punjab. Thus results like those described above should serve as an input into the development decision-making process, but should not be the sole determinant of the outcome of that process.

Several sensitivity analyses were carried out to determine the sensitivity of the results of the economic analysis to certain key assumptions and parameters. Specifically, an EIRR was determined for the total project in the following two cases: (i) the saturation rate for all types of consumers increases after the second project-year at only 90 percent of the rate assumed in the base case; and (ii) investment costs increase by 10 percent or 20 percent. $^{10}$ Results are summarized in Table 1.

The result of the slower growth in saturation assumed in the first sensitivity analysis is that the EIRR is reduced by approximately one-half. This finding emphasizes how important it is to attain the assumed rate of growth of saturation. WAPDA and the Government should be prepared to undertake load-promotion activities if necessary. Conversely, if the potential demand for electricity is high, they should attempt to ensure that consumers are rapidly connected. Results from the second sensitivity analysis indicate that 10 percent and 20 percent increases in investment costs reduce the EIRR to a considerably lesser extent. The reductions in the EIRR are relatively small since investment costs are small relative to operating costs when compared over the entire 25 -year lifetime of the project.

\section{SUMMARY AND CONCLUSIONS}

This paper discusses some of the economic benefits which are likely to result from rural electrification and, then, a method of estimating these benefits is outlined. In addition, an appropriate approach for measuring the economic costs of rural electrification is described.

The methodology for measuring the benefits and costs of rural electrification is then applied in a case-study of a proposed rural electrification project in Pakistan. The results of this case-study suggest that there is a reasonable, strong economic justification for the project (the EIRR is 11.9 percent), especially in light of the fact that some of the benefits of electrification cannot be easily quantified. There is considerable variation in the EIRRs for the electrification schemes in different provinces. Specifically, they are highest in the Punjab and Sind where the length of $11-\mathrm{KV}$ lines needed to reach villages is shortest and the average village size is largest.

${ }^{10}$ The saturation rate measures the percentage of eligible consumers who actually connect 
Conversely, EIRRs are lowest in the N.-W.F.P. and Baluchistan where 11-KV lines are longest and villages are smallest. Thus the economic justification for rural electrification appears strongest in the Punjab and Sind. However, other social and political factors must also be considered when decisions are made concerning investments in rural electrification.

Economic theory emphasizes the efficiency gains resulting from setting prices equal to marginal cost. Within the context of the distributional objectives of this rural electrification project, tariffs should be set as close as possible to the long-run marginal cost of supply; and, in fact, the estimates of cost savings resulting from electrification, which were presented above, suggest that it might be possible to increase tariffs without seriously reducing connection rates in the electrification areas.

Finally, this paper highlights several important areas for future research. First, more work needs to be done concerning what the likely economic benefits of electrification will be and how they can be measured. Secondly, consideration should be given to how rural electrification programmes can be more closely integrated with other regional development programmes - such as SCARP (Salinity Control and Reclamation Project) in Pakistan. Finally, the most efficient way of supplying electricity to rural electrification consumers should be investigated. Currently, connecting rural consumers to the national grid seems to be the preferred alternative. However, with rising fuel prices and improving technologies, alternative methods of supplying power (such as solar, wind, biogas, and mini-hydro) should be given serious consideration.

\section{REFERENCES}

1. Anderson, Dennis, and Ralph Turvey. Electricity Economics. Baltimore: Johns Hopkins University Press. 1977.

2. Munasinghe, M. Electric Power Pricing Policy. Washington, D.C: World Bank. July 1979 (World Bank Staff Working Paper No. 340)

3. Munasinghe, Mohan, and Mark Gellerson. "Determining Marginal Cost Based Electricity Tariffs: Case Study of the WAPDA System". June 1980. (Mimeographed)

4. Munasinghe, Mohan, and Jeremy J. Warford. Electricity Pricing: Theory and Case Studies. Baltimore: Johns Hopkins University Press. 1982.

5. Squire, Lyn, and Herman G. van der Tak. Economic Analysis of Projects. Baltimore: Johns Hopkins University Press. 1975.

6. Steiner, P. "Peak Loads and Efficient Pricing". Quarterly Journal of Economics. 1957.

7. Williamson, O. "Peak Load Pricing and Optimal Capacity under Indivisibility Constraints". American Economic Review. Vol. LVI, No. 4, Part I. 1966. 